\title{
The influence of strategic networks and logistics integration on firm performance among small and medium enterprises
}

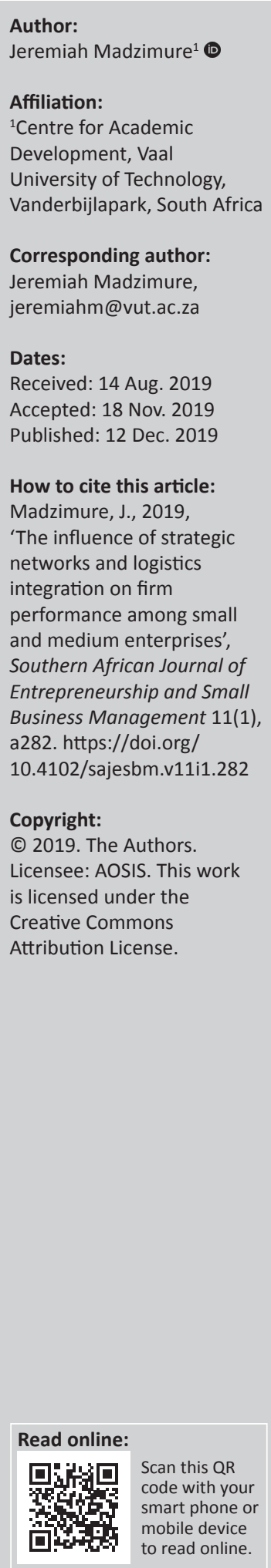

Background: In order to stay competitive in business and improve performance, small and medium enterprises (SMEs) need to make use of business networking and logistics integration. Strategic networking and logistics integration in business have become critical as they allow supplier partnering, exchange of vital information or access to valuable resources allowing innovation, gaining access to additional resources, sharing risks and costs, which is required for enhancing firm performance. Strategic networks and logistics integration across partnering firms have therefore become paramount to supply chain management as they are critical to firm performance. Most studies in this subject matter have focussed on larger firms. It became imperative for this study to focus on SMEs.

Objectives: The purpose of this study was to examine the influence of strategic networks and logistics integration on firm performance in SMEs in the Vaal Triangle.

Method: A quantitative research design was adopted in this study. The owners and managers of 137 SMEs completed the survey questionnaire. Confirmatory factor analysis (CFA) was conducted to assess the psychometric properties of the measurement scales. Path modelling techniques were used to test the proposed hypotheses.

Results: The results indicate that strategic networks had a positive and significant influence on logistics integration and firm performance. Furthermore, logistics integration had a strong positive and significant influence on firm performance.

Conclusion: This study sheds light on the possibility of enhancing the overall performance of SMEs by establishing and empirically testing the relationships between logistics integration and strategic networks and firm performance. Moreover, the findings of the study provide useful insights into how SMEs should benefit from business networking and logistics integration to improve their performance.

Keywords: strategic networking; logistics integration; company performance; SMEs; enhancing; supplier partnering; South Africa.

\section{Introduction}

The recognised relationship between firm performance and strategic relationships and logistics integration has prompted managers, researchers and practitioners alike to seek better understanding of the performance of small and medium enterprises (SMEs).

Strategic networking is one of the most important aspects of supply chain management (SCM) that contribute to the growth of SMEs (Parker 2008:627), and its different types, definitions and roles have been extensively studied (Mayaka 2015; Tooksoon \& Mudor 2012:273). Furthermore, strategic networks, sometimes known as business networks, is defined as a set of two or more connected business relationships in which exchange in one relationship is contingent upon exchange (or non-exchange) in another (Ricciardi 2014:151). It can be said that strategic networks are key to the success of the organisation and supply chains (Jarillo 1988:31; Mbanje \& Lunga 2015). However, despite its importance in business, there is little empirical evidence as to how both strategic networks and logistics integration influence firm performance. Some studies have been conducted with only one variable - either strategic network or logistics integration's influence on firm performance ( $\mathrm{Li}$ 2014). In addition to this, many studies have also been conducted on the impact of networking on the performance of SMEs (Ricciardi 2014:113; Tooksoon \& Mudor 2012:272), but little information is available on the impact of networking on the performance of SMEs in African countries. 
Strategic network is regarded as a resource, which can help firms acquire additional knowledge and information regarding their business and contribute to the exchange of various resources, such as financial resources and skills, thereby facilitating the improvement of company performance. Overall, strategic networking plays a vital role in improving the integration of logistics activities from supplier to the final customer and vice-versa (Bowersox \& Daugherty 1995:71; Prashantham \& Dhanaraj 2010:967).

The aim of this study was to determine the influence of strategic networks and logistics integration on firm performance among SMEs. The study was conducted in the Vaal Triangle, Southern Gauteng, South Africa.

The next section focusses on a literature review, regarding the SMEs in South Africa, strategic networking, logistics integration and firm performance, followed by conceptual framework and hypothesis development; thereafter, research methodology is discussed followed by the results of the study. Finally, the article comes to a conclusion about the implications of the study, together with the recommendations.

\section{Literature review}

\section{Small and medium enterprises in South Africa}

In South Africa, SMEs play a critical role in the country's economy. Small and medium enterprises contribute between $52 \%$ and $57 \%$ of the country's gross domestic product (GDP) and up to $61 \%$ of the overall employment in South Africa (Abhor \& Quartey 2010:225). Small and medium enterprises play a crucial role in creating employment in an economy (Statistics South Africa [STATS SA] 2019:279). Moreover, SMEs play a very important role in SCM as they may serve as producers, distributors, retailers, as well as customers (Doern 2009:276; Maiga 2016:2). Therefore, it is not surprising that SMEs are the backbone of most economies in the world, including South Africa, as they are the creators of most jobs in the economy.

The National Small Business Act No. 26 of South Africa 1996, as amended in 2003, defines SME as:

\footnotetext{
... a separate and distinct entity including co-operative enterprises and non-governmental organisations managed by one owner or more, including its branches or subsidiaries if any is predominantly carried out in any sector or subsector of the economy mentioned in the schedule of size standards and can be classified as a SME by satisfying the criteria mentioned in the schedule of size standards. (Republic of South Africa 1996:1)
}

According to the Government Gazette (2003:8), a small retail enterprise in South Africa is one that employees 50 people or less and has a total turnover of up to R19 million, with a total asset value of $\mathrm{R} 3 \mathrm{~m}$. A medium retail enterprise employs from 50 up to 200 people and has a total turnover of R39m, with a total asset value of R6m. Hence, this study focussed on SMEs.

\section{Strategic networks}

According to Parker (2008:628) and Nogues (2014:342), a business network is a group of entrepreneurs that voluntarily share knowledge and experiences. Jarillo (1988:31) defined strategic networks as 'long-term, purposeful arrangements among distinct but related for-profit organisations that allow firms in them to gain or sustain competitive advantage vis-à-vis their competitors outside the network'. Therefore, in this study, strategic networking refers to the process through which firms leverage specialisation, effectively allocate transformational resources and optimise support through knowledge and information, thereby minimising company costs and consequently improving the performance of the firm.

\section{Logistics integration}

Logistics integration refers to collaborative working and implies joint planning, joint product development, mutual exchange of information and integrated information systems, cross-coordination on several levels in the companies on the network, long-term cooperation, fair sharing of risks and benefits (Lai, Wong \& Cheng 2010:273; Taghipour et al. 2015). Logistics integration does not only refer to integration and collaboration within the organisation but also includes the collaboration with the suppliers upstream and distributors, and customers downstream. Thus, within organisations, logistics integration is crucial as it provides a significant competitive advantage, which leads to lower operational costs, as well improvement in value creation (Eckenhofer 2011:128; Lai et al. 2010:274).

\section{Firm performance}

Firm performance is defined as the performance of various processes included within the firm's supply chain function (Srinivasan, Mukherjee \& Gaur 2011:268). One of the key aspects to successful company performance is cooperation and mutual decision-making between trading partners. Companies try to improve their performance in terms of cost, delays, adaptability, variety and traceability. Collaboration practices and information exchanges between partners become essential within any supply chain, as they contribute to performance (Sakka \& BottaGenoulaz 2009:1). An effective performance measurement is essential for firm performance because it provides the basis to understand the system, as well as information about the results of system efforts to supply chain partners (Anderson \& Reeb 2003:1301; Chen, Yang \& Li 2007:524). Overall, firm performance is recognised as an important factor for improving competitive advantage (Chang, Tsai \& Hsu 2013:35).

\section{Conceptual framework and hypothesis development}

The research model is shown in Figure 1 linking the three hypotheses postulated. 


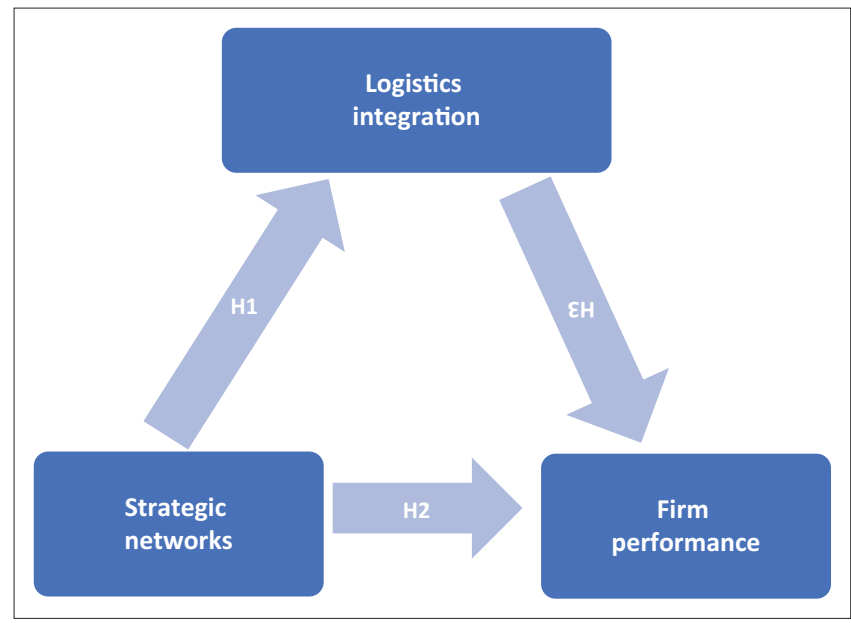

FIGURE 1: Conceptual framework.

\section{Strategic networks and logistics integration}

A strategic network is regarded as a resource that can help firms acquire additional knowledge and information regarding their business and contribute to the exchange of various resources such as financial resources and skills (Sandberg 2007). Logistics integration in this study refers to collaboration, integration of stakeholders, as well as cooperation in the firm's logistics activities. Thus, confirming our first hypothesis:

H1: Strategic networks have a positive influence on logistics integration.

\section{Strategic networks and firm performance}

Vermeulen, Niemann and Kotzé (2016) and Wheelen and Hungar (2002:125) state that strategic networking is an agreement between firms to do business together in ways that go beyond normal company-to-company dealings but fall short of a merger or a full partnership. The findings of Tooksoon and Mudor (2012) showed that the business network was statistically significant and positively associated with performance.

Ge, Hisrich and Dong (2009:189) studied the impact of networking on the performance of SMEs. This study was conducted by taking a total sample of 227 firms from three cities in China and found that the outcome of the network was positively related to firm performance.

In addition to this, some previous studies have shown that networks with other firms are positively associated with the performance of the firm (Jack, Dodd \& Anderson 2008:121; Prashantham \& Dhanaraj 2010:231; Watson 2007:23).

It is clear from this that strategic networking not only involves social networks but also involves knowledge networks. Firms that are involved in strategic networking are intended to gain knowledge and impart that knowledge to ensure the success of their business. In light of the foregoing, it is hypothesised that:
H2: The strategic networks have a positive influence on firm performance.

\section{Logistics integration and firm performance}

Logistics integration is closely linked to firm performance. So it can be postulated that logistics integration can help firms improve linkage between suppliers, which ensures that goods are received on time, leading to improved company performance (Kang \& Moon 2016:307; Van der Vaat \& Van Donk 2008:121).

Based on the aforementioned, the following hypothesis is postulated:

H3: Logistics integration has a positive influence on firm performance.

\section{Research method and design}

This study adopted a quantitative research methodology to help establish the statistical evidence on the strengths of the influence of supply strategic networks and logistics integration on firm performance. The quantitative method also helps the researcher determine causal relationships between variables (Cooper \& Schindler 2011:217; Sekaran \& Bougie 2009:221). In addition, the data from quantitative methodology can be interpreted using statistical analysis.

\section{Sample and data collection}

The data for this study were collected from SME managers and owners in the Vaal Triangle, Southern Gauteng, South Africa. The population for the study comprised 1543 SMEs owners and managers in the Vaal Triangle. The unit of analysis was the SME owners and managers in the Vaal Triangle. A convenience sampling method was used to obtain a sample of 250 SMEs. Student tutors were trained prior to the distribution and collection of 250 questionnaires. Out of the total questionnaires distributed, only 137 were fully completed and were used for final data analysis of this study. This represents a response rate of $54.8 \%$. Regarding ethical considerations, all respondents signed a formal consent form before completing the questionnaire. Furthermore, information provided by participants or respondents was treated with utmost confidentiality, and anonymity was fully guaranteed. The names of respondents did not appear on the questionnaire or data, as anonymity was promised to all respondents.

\section{Measurement instrument and questionnaire design}

'Logistics integration' was measured using a six-item scale adapted from Chen and Paulraj (2004:148), while 'strategic networks' used a five-item scale adapted from Chinomona and Pooe (2013:7).

'Firm performance' was measured using a four-item scale, which was adopted from Chinomona and Pooe (2013:7). 
All were measured on a five-point Likert-type scale that was anchored by 1 (strongly disagree) to 5 (strongly agree) to express the degree of agreement. The Likert scale was used because it was easy to analyse data, draw conclusions and graphs, as the study adopted a quantitative study design.

The layout of the questionnaire is provided in Table 1.

\section{Data analysis}

Data were subjected to statistical analysis using the following techniques: Descriptive statistics, confirmatory factor analysis (CFA) model fit and hypothesis testing using structural equation modelling (SEM) with the Analysis of Moment Structures (AMOS) programme version 24.0. The respondents' biographic information and the composition of the sample were analysed using descriptive statistics in the form of frequencies and charts. The other constructs were analysed using the Statistical Package for Social Sciences (SPSS), version 24.0 for Windows. The descriptive statistics, CFA, model fit and SEM are discussed in the next section of research results. The SEM was used in this study to analyse the relationships between the constructs.

\section{Ethical considerations}

This article followed all ethical standards for carrying out research without direct contact with human or animal subjects.

\section{Research results}

This section consists of three sub-sections, namely, the demographic profile of respondents, CFA and path modelling.

\section{Profile of respondents}

Table 2 presents the profile of all participants in this study.

A descriptive analysis incorporating the demographic information regarding the supply chain professionals and SME profile was conducted. A descriptive analysis of Section A (demographics and SME profile) is discussed in the foregoing section, which consists of gender, experience in the industry, number of employees, type of sector and rate of turnover. It was important to first create a descriptive demographic and SME profile to enhance the researcher's understanding of the important aspects of key personnel and the SME. A summarised frequency table of demographics and SME profile is represented in Table 2.

Table 3 shows the demographics of the respondents. Males constitute $74 \%$, while females represent $26 \%$. The majority of the respondents (29\%) have worked in their firms between 5 and 10 years. Those firms that employed between 101 and 150 employees were $41 \%$ and those that employed between 151 and 200 were 36\%, meaning that the majority of the employees surveyed, work in the medium firms. Though not indicated in the table, only one SME owner or manager had a
TABLE 1: Layout of the questionnaire.

\begin{tabular}{llc}
\hline Section & Topic of section & Number of questions \\
\hline A & Demographic details & 3 \\
B & Strategic networks & 6 \\
C & Logistics integration & 5 \\
D & Firm performance & 4 \\
\hline Total number of questions & - & $\mathbf{1 8}$ \\
\hline
\end{tabular}

TABLE 2: Combined demographics and small and medium enterprises profile.

\begin{tabular}{llcc}
\hline Variables & Categories & $\boldsymbol{N}$ & $\mathbf{\%}$ \\
\hline Gender & Male & 102 & 74 \\
& Female & 35 & 26 \\
& Total & $\mathbf{1 3 7}$ & $\mathbf{1 0 0}$ \\
Number of years in & Less than 1 year & 12 & 9 \\
the industry & Between 1 and 5 years & 30 & 22 \\
& Between 5 and 10 years & 40 & 29 \\
& Between 10 and 15 years & 35 & 26 \\
& 15 years and above & 20 & 14 \\
& Total & 137 & 100 \\
Number of employees & Less than 50 & 12 & 9 \\
in the company & 51-100 & 19 & 14 \\
& $101-150$ & 56 & 41 \\
& $151-200$ & 50 & 36 \\
& Total & 137 & 100 \\
\hline
\end{tabular}

PhD qualification, 22 had a Master's degree, while 97 had a diploma and/or degree qualification. A total of 27 owners and/or managers had matric certificates but no further qualifications. The next section discusses the CFA.

\section{Confirmatory factor analysis}

Confirmatory factor analysis is 'a way of testing how well variables measured represents a smaller number of constructs' (Hair et al. 2014:602). Confirmatory factor analysis was conducted using the AMOS, version 24.0, to assess psychometric properties of the measurement scales.

In this study, model fit was ascertained by using the following indices: Chi-square/degrees of freedom, Comparative-fit-index (CFI), Incremental fit index (IFI), Normed fit index (NFI), Tucker-Lewis index (TLI) and Random Measure of Standard Error Approximation (RMSEA). The acceptable thresholds should be equal to or higher than 0.90 for CFI, IFI and NFI (Hair et al. 2016:345); for Chi-square/degrees of freedom, a ratio of 3:1 or less is recommended; RMSEA value should be equal to or less than 0.08 (Lysons \& Farrington 2012:586). The results of CFA are reported in Table 3.

A CFA model of the three study constructs was assessed to check the model fit (Hove 2015). The results are reported in Table 4.

Table 4 indicates that the measurement model yielded a ratio of chi-square value to degree-of-freedom of 1.49 (Hove 2015). The recommended threshold range is between 1 and 3 (Cooper \& Schindler 2011). The current study has a value far below 3 . As such, the chi-square to degree-of-freedom value of 1.49 in this study is accepted and reflects a good model fit. 
TABLE 3: Accuracy analysis statistics.

\begin{tabular}{|c|c|c|c|c|c|c|c|c|}
\hline \multirow[t]{2}{*}{ Research construct } & \multicolumn{2}{|c|}{ Descriptive statistics } & \multicolumn{2}{|c|}{ Cronbach's test } & \multirow[t]{2}{*}{ CR } & \multirow[t]{2}{*}{ AVE } & \multirow[t]{2}{*}{ Factor loading } & \multirow[t]{2}{*}{ Highest SV } \\
\hline & Mean & SD & Item total & Alpha value & & & & \\
\hline SN & 4.12 & 0.56 & - & 0.71 & 0.88 & 0.60 & - & 0.47 \\
\hline SN 1 & - & - & 0.53 & - & - & - & 0.57 & - \\
\hline SN 2 & - & - & 0.48 & - & - & - & 0.48 & - \\
\hline SN 3 & - & - & 0.40 & - & - & - & 0.54 & - \\
\hline SN 4 & - & - & 0.48 & - & - & - & 0.59 & - \\
\hline LI & 4.13 & 0.53 & - & 0.75 & 0.94 & 0.79 & - & 0.58 \\
\hline 니 1 & - & - & 0.51 & - & - & - & 0.61 & - \\
\hline LI 2 & - & - & 0.59 & - & - & - & 0.73 & - \\
\hline LI 3 & - & - & 0.62 & - & - & - & 0.69 & - \\
\hline LI 4 & - & - & 0.49 & - & - & - & 0.61 & - \\
\hline FP & 4.62 & 0.54 & - & 0.72 & 0.88 & 0.84 & - & 0.66 \\
\hline FP 1 & - & - & 0.51 & - & - & - & 0.63 & - \\
\hline FP 3 & - & - & 0.55 & - & - & - & 0.68 & - \\
\hline
\end{tabular}

SD, standard deviation; CR, composite reliability; AVE, average variance extracted; SV, shared variance; LI, logistics integration; SN, strategic networks; FP, firm performance.

TABLE 4: Confirmatory factor analysis model fit indices results.

\begin{tabular}{lc}
\hline Measures & Values \\
\hline Contrast media-induced nephropathy (CMIN) & 1046.592 \\
Chi-squared/df & 1.49 \\
The incremental fit index (IFI) & 0.95 \\
The Tucker-Lewis index (TLI) & 0.97 \\
The Comparative-fit-index (CFI) & 0.95 \\
The Root Mean Square Error of Approximation (RMSEA) & 0.02 \\
\hline
\end{tabular}

$d f$, degrees of freedom

TABLE 5: Structural equation modelling model fit indices results.

\begin{tabular}{lr}
\hline Measures & Values \\
\hline Contrast media-induced nephropathy (CMIN) & 1038.61 \\
Chi-square/df & 1.46 \\
The incremental fit index (IFI) & 0.93 \\
The Tucker-Lewis index (TLI) & 0.91 \\
The Comparative-fit-index (CFI) & 0.92 \\
The Root Mean Square Error of Approximation (RMSEA) & 0.03 \\
\hline
\end{tabular}

$d f$, degrees of freedom.

Table 5 also shows IFI, TLI and CFI values $(0.95,0.97$ and 0.95 , respectively) that are above the recommended threshold of 0.9 or above (Berndt \& Petzer 2011:348). This further reflects a good model fit. Table 5 further reports an RMSEA value of 0.02 and is less than 0.08 ; thus, it yields a reasonable model fit. Overall, all these measures confirm a robust and acceptable model fit (Schreiber et al. 2006:330). The next section discusses the path modelling results.

\section{Path modelling results}

Berndt and Petzer (2011:348)) suggest that the goal of path analysis is 'to provide plausible explanations of observed correlations by constructing models of cause-and-effect relations'. Path analysis allows path coefficients (the relationship between variables) to be determined. In addition, path analysis requires recursivity (that the path direction is one way with no feedback loops) (Cooper \& Schindler 2011). The advantage of path analysis is that the researcher can see which variables exert effects on others. Table 5 shows the SEM model fit indices results.
As shown in Table 5, this study reports a chi-square/df value of 1.46 as indicative of a good model fit. Table 5 further shows IFI, CFI and TLI values (0.93, 0.91 and 0.92, respectively) that are above the recommended threshold of 0.9 or above. These results further confirm that the estimated model fits well the sample data in this study, which provides a good model fit (Hove 2015). The table also depicts an RMSEA value of 0.03 , which provides a very good model fit. Overall, the model fit indices provide a good overall fitness of the SEM model to the specified sample data. The results of hypothesis tests are reported in Table 6 and show that all the three hypotheses were supported as the path coefficient were all significant.

\section{Discussion and conclusion}

This study shows that both strategic networks and logistics integration have positive effects on firm performance.

Strategic networks also show a strong positive on logistics integration. Overall, the empirical results confirm the important role of strategic networking and logistics integration in increasing company performance. The results of the study support all three the hyptheses. The findings of this study are consistent with those in previous literature, thus providing additional evidence in this line of research. Examples of similar findings include Bonner, Kim and Cavusgil (2005); Chinomona and Pooe (2013:6); Sawyerr, McGee and Peterson (2003); Sukati et al. (2011), and Watson (2007:870) whose studies found that logistics integration and strategic networking positively influence firm performance. The strong positive relationship on these constructs could be that the firms are sharing important business information and always integrate their logistics function.

Overall, the findings of this study confirm that there are close links between strategic networks, logistics integration and firm performance. Thus, this study argues that a combination of strategic networks and logistics integration can have a greater positive and significant effect on firm performance. 
TABLE 6: Structural equation modelling results.

\begin{tabular}{lcccccc}
\hline Variables & Path & Variables & Hypothesis & Path coefficient & Standard error & Critical region \\
\hline SN & $\rightarrow$ & LI & H1 & 0.71 & 0.153 & 2126 \\
SN & $\rightarrow$ & FP & H2 & 0.49 & 0.057 & 5000 \\
LI & $\rightarrow$ & FP & H3 & 0.55 & 0.046 & 4810 \\
\hline
\end{tabular}

LI, logistics integration; $\mathrm{SN}$, strategic networks; $\mathrm{FP}$, firm performance; $\mathrm{H}$, hypothesis; $\mathrm{C}$, significance level.

$*, p<0.05, * *, p<0.001$.

\section{Research contribution and implications of the study}

The findings of this study can enhance SME owners' and managers' understanding of how company performance can be improved through strategic networking and logistics integration. The Government of South Africa can plan and formulate policies to foster the growth of SMEs with more understanding of the linkage between strategic networking, logistics integration and firm performance.

Strategic networks and logistics integration are important issues that firms in developing countries such as South Africa must address. The findings of this study show that forming strategic networks and promoting the integration of logistics activities are valid strategies to improve firm performance. This study, therefore, reinforces the importance of SMEs managers and owners to build strategic networks with their suppliers and other firms as these have proven to have positive effects on firm performance.

The findings of the study have shown that strategic networking contributes significantly to the performance of the firm. Therefore, SMEs managers and owners are encouraged to engage in active networking with other firms, especially those that are relevant to the business in which the firm operates.

Considering these findings, this study also reinforces the importance of SMEs managers and owners to build strategic relationships with business partners for effective networking as this is likely to enhance the performance of the firm. Managerially, the study demonstrates the need for firms to have strong networking with supplier partners, as well the need to effectively implement a good logistics integration, as these will lead to improvement in firm performance. Over and above, this study sheds light on the possibility of enhancing the overall performance of SMEs by establishing and empirically testing the relationships between logistics integration and strategic networks and firm performance.

\section{Limitations and future research}

Like other studies, this research has some limitations. The major limitation for this study was that the sample was drawn from one region of South Africa. Future research can consider other provinces of South Africa, as well as incorporate larger firms for comparison purposes and for the generalisability of results. Also, in this study, the perceptions of only the SMEs owners and managers were incorporated. These people may be biased in evaluating internal and external organisational issues. It would be beneficial to include all stakeholders, including suppliers and customers, concerning issues of strategic networks and logistics integration.

Another limitation of this study was the small sample size which made it difficult to generalise these results. Future research with a large sample size should be conducted in order to contribute to a generalisable understanding of the research issues.

This research examined the influence of strategic networks and logistics integration on firm performance observed at one point in time; future research is suggested to be conducted via longitudinal study. This could provide a clearer insight into the impact of strategic networks and logistics integration on firm performance.

This study focusses on the mediating role of logistics integration in the relationship between strategic networks and firm performance; future research might examine other mediating or moderating factors that may affect this relationship such as trust, information sharing, network structure and firm size, among others.

Another area of research could be on the impact of business networking on organisational innovation and excellence. The other study suggested could be on the effect of the external environment on strategic networking in SMEs. The relationship between strategic networking antecedents/ corollaries (such as commitment, trust, reputation, communication and cooperation) and firm performance could also be investigated and might reveal interesting results. Finally, this study could have also used both the quantitative and qualitative methods (mixed method approach) to understand the deeper nuances.

\section{Acknowledgements}

The author is grateful to the Almighty God and his beloved family. He also thanks Mothusi Samosamo for drawing the diagrams.

\section{Competing interests}

The author declares that there are no financial or personal relationships that may have inappropriately influenced him in writing this article.

\section{Author's contributions}

I declare that I am the sole author of this research article. 


\section{Funding information}

This research received no specific grant from any funding agency in the public, commercial or not-for-profit sectors.

\section{Data availability statement}

Data sharing is not applicable to this article as no new data were created or analysed in this study.

\section{Disclaimer}

The views and opinions expressed in this article are the author's own and not an official position of the institution or the funder.

\section{References}

Abhor, J. \& Quartey, P., 2010, 'Issues in SME development in Ghana \& South Africa', International Journal of Finance \& Economics 39, 218-228. https://doi. org/10.1111/1540-6261.00567

Anderson, R.C. \& Reeb, D.M., 2003, 'Founding-family ownership and firm performance: Evidence from S\&P 500', Journal of Finance 58, 1301-1328.

Berndt, A. \& Petzer, D., 2011, Marketing research, Pearson Education, Cape Town.

Bonner, J.M., Kim, D. \& Cavusgil, S.T., 2005, 'Self-perceived strategic network identity and its effects on market performance in alliance relationships', Journal of Business Research 58(10), 1371-1380. https://doi.org/10.1016/j.jbusres.2004.07.002

Bowersox, D.J. \& Daugherty, P.J., 1995, 'Logistics paradigm: The impact of information technology', Journal of Business Logistics 16(1), 65-80.

Chang, H.H., Tsai, Y.C. \& Hsu, C.H., 2013, 'E-procurement \& supply chain performance', International Journal of Management 18(1), 34-51. https://doi. org/10.1108/13598541311293168

Chen, I.J. \& Paulraj, A., 2004, 'Towards a theory of supply chain management: The constructs and measurements', Journal of Operations Management 22(2), 119-150. https://doi.org/10.1016/j.jom.2003.12.007

Chen, M.C., Yang, T. \& Li, H.C., 2007, 'Evaluating the supply chain performance of IT-based inter-enterprise collaboration', Information \& Management 44(6), 524-534. https://doi.org/10.1016/j.im.2007.02.005

Chinomona, R. \& Pooe, R.I.D., 2013, 'The influence of logistics integration on information sharing and business performance: The case of small and medium enterprises in South Africa', Journal of Transport and Supply Chain Management 7(1), 1-9. https://doi.org/10.4102/jtscm.v7i1.92

Cooper, D.R. \& Schindler, P., 2011, Business research methods, McGraw-Hill, New York.

Doern, R., 2009, 'Investigating barriers to SME growth and development in transition environments: A critique and suggestions for developing the methodology', International Small Business Journal 27(3), 275-305. https://doi.org/10.1177/ 0266242609102275

Eckenhofer, E.M., 2011, 'Network management as a way to manage intellectual capital', in Proceedings of the 12th European Conference on Knowledge Management - ECKM 2011, University of Passau, Passau, September 1-2, 2011.

Ge, B., Hisrich, R.D. \& Dong, B., 2009, 'Networking, resource acquisition, and the performance of small and medium-sized enterprises: An empirical study of three major cities in China', Managing Global Transitions 7(3), 221-239.

Government Gazette, 2003, No 26 National Small Business Amendment Act, vol. 461 pp. 1-10, Parliament of the Republic of South Africa, Cape Town.

Hair, J.F., Black, W.C., Babin, B.J. \& Anderson, R.E., 2014, Multivariate data analysis, 7th edn., Pearson New International Edition, London.

Hair, J.F., Tomas, G., Hult, M., Ringle, M.C. \& Sarstedt, M., 2016, A Primer on Partia Least Squares Structural Equation Modeling (PLS-SEM), 2nd edn., Sage, Thousand Oaks, CA.

Hove, P., 2015, 'The influence of supply chain practice on supply chain performance in South Africa', PhD thesis, Business, Logistics, Faculty of Management Sciences, Vaal University of Technology, viewed n.d., from http://hdl.handle.net/10352/320

Jack, S., Dodd, S.D. \& Anderson, A.R., 2008, 'Change and the development of entrepreneurial networks over time: A processual perspective', Entrepreneurship \& Regional Development 20(2), 125-159. https://doi.org/10.1080/08985620 701645027

Jarillo, J.C., 1988, 'On strategic networks', Strategic Management Journal 9(1), 31-41. https://doi.org/10.1002/smj.4250090104
Kang, S. \& Moon, T., 2016, 'Supply chain integration and collaboration for improving supply chain performance: A dynamic capability theory perspective', 49th Hawail international conference on system sciences, Washington, DC, United States, international conference on system
January 05-08, 2016, pp. 307-316.

Lai, K.H., Wong, C.W. \& Cheng, T.C.E., 2010, 'Bundling digitized logistics activities and its performance implications', Industrial Marketing Management 39(2), 273-286. https://doi.org/10.1016/j.indmarman.2008.08.002

Li, X., 2014, 'Operations management of logistics and supply chain: Issues and directions', Discrete Dynamics in Nature and Society, volume 2014, Article ID 701938, 7 pages. https://doi.org/10.1155/2014/701938

Lysons, K. \& Farrington, B., 2012, Purchasing and supply chain management, 8th edn., Prentice-Hall, London.

Maiga, A.S., 2016, 'Assessing the impact of supply chain integration on firm competitive capability', International Journal of Operations Research and Information System 7(1), 1-2. https://doi.org/10.4018/IJORIS.2016010101

Mayaka, R.L., 2015, 'Effect of supply chain management practices on performance of Barclays Bank of Kenya Limited', Master of Business Administration (Procurement \& Supply Chain Management) research project, University of Nairobi, Nairobi, Kenya.

Mbanje, S. \& Lunga, J., 2015, Fundamental principles of supply chain management, Van Schaik, Pretoria.

Nogues, G., 2014, The supply chain of the future, Illinois Institute of Technology special project, Illinois Institute of Technology Publishers, Chicago, IL.

Parker, S., 2008, 'The economics of formal business network', Journal of Business Venturing 23(6), 627-640. https://doi.org/10.1016/j.jbusvent.2008. 01.003

Prashantham, S. \& Dhanaraj, C., 2010, 'The dynamic influence of social capital on the international growth of new ventures', Journal of Management Studies 47(6), 967-994. https://doi.org/10.1111/j.1467-6486.2009.00904.x

Republic of South Africa, 1996, The National Small Business Act No. 26 of South Africa 1996, Government Printing Works, Pretoria.

Ricciardi, F., 2014, Innovation processes in business networks, advances in information systems and business engineering, Springer Fachmedien, Wiesbaden.

Sakka, O. \& Botta-Genoulaz, V., 2009, 'A model of factors influencing the supply chain performance', viewed n.d., from https://hal.archives-ouvertes.fr/hal-00389134/ document

Sandberg, E., 2007, 'Logistics collaboration in supply chains: Practice vs theory', International Journal of Logistics Management 18(2), 274-293. https://doi. org/10.1108/09574090710816977

Sawyerr, O.O., McGee, J. \& Peterson, M., 2003, 'Perceived uncertainty and firm performance in SMEs: The role of personal networking activities', International Small Business Journal 21(3), 269-278. https://doi.org/10.1177/ 02662426030213002

Schreiber, J.B., Stage, F.K., King, J., Nora, A. \& Barlow, E.A., 2006, 'Reporting structural equation modeling and confirmatory factor analysis results: A review', The Journal of Educational Research 99(6), 323-338. https://doi.org/10.3200/JOER.99.6. 323-338

Sekaran, U. \& Bougie, R., 2009, Research methods for business: A skill-building approach, 5th edn., John Wiley, New York.

Srinivasan, M., Mukherjee, D. \& Gaur, A.S., 2011, 'Buyer-supplier partnership quality and supply chain performance: Moderating role of risks and environmental uncertainty', European Management Journal 29, 260-271. https://doi. org/10.1016/j.emj.2011.02.004

Statistics South Africa (STATS SA), 2019, 'Monthly Archives: July 2019', viewed 10 November 2019, from http://www.statssa.gov.za/?m=201907

Sukati, I., Hamid, A.B.A., Baharun, R., Tat, H.H. \& Said, F., 2011, 'An investigation of the relationship between supply chain management practices and competitive advantage of the firm', Contemporary Marketing Review 1(4), 1-13.

Taghipour, M., Bagheri, M., Khodarezaei, M. \& Farid, F., 2015, 'Supply chain performance evaluation in the IT industry', International Journal of Research and Reviews in Applied Sciences 23(2), 144-156.

Tooksoon, P. \& Mudor, H., 2012, 'Commitment to networking and export performance: Evidence from Thai SME's in agro-based sector', Information Management and Business Review 4(5), 268-274.

Van der Vaat, T. \& Van Donk, D.P., 2008, 'A critical review of survey-based research in supply chain integration', International Journal of Production Economics 111(1), supply chain integration', International Journal of

Vermeulen, Y., Niemann, W. \& Kotzé, T., 2016, 'Supply chain integration: A qualitative exploration of perspectives from plastic manufacturers in Gauteng', Journal of Transport and Supply Chain Management 10(1), 451-459. https://doi.org/ of Transport and supply

Watson, J., 2007, 'Modeling the relationship between networking and firm performance', Journal of Business Venturing 22(6), 852-874. https://doi. org/10.1016/j.jbusvent.2006.08.001

Wheelen, K.M. \& Hungar, G., 2002, Revolutionizing product development, Free Press, New York, NY. 